\title{
Anterior pontine cavernoma: what should be done?
}

\begin{abstract}
Introduction: Anterior pontine cavernomais a rare pathology with difficult access; it predominantly occurs in middle-aged patients with a high risk of bleeding and rebleeding. There is a direct association with genetic inheritance due to the CCM1, CCM2 and CCM3 genes, and if it is associated, there is a higher risk of severity.

Materials and methods: Analysis of PUBMED publications about ventral pontine cavernomas, anterolateral pontine cavernomas, and main surgical approaches.

Results and discussion: Pontine cavernomas have a bleeding risk of 5\% per year and rebleeding of $30 \%$ per year; therefore, it is a surgical pathology in which most authors approach from four to six weeks after bleeding for total resection and curative purposes. There are different approaches and they depend on the topography of the lesion and the surgeon`s ability; technologies such as monitoring, neuronavigation, and tractography must be used to reduce the risk of lesions. The most used approaches are retrosigmoid, presigmoid, and anterior transpetrosal; the use of endoscopic approaches has been increasing recently.
\end{abstract}

Conclusion: Anterior pontine cavernoma is a severe pathology that must be surgically treated to decrease the risk of bleeding and rebleeding.

Keywords: cavernoma, pontine cavernoma, cavernous angioma, pontine hemorrhage
Volume 3 Issue 3 - 2017

\author{
Maick Willen Fernandes Neves,' Paulo \\ Henrique Pires de Aguiar, ${ }^{2}$ Telmo Augusto \\ Barba Belsuzarri,' Fernando Antonio de \\ Melo Filho,' Sergio Hideki Suzuki, ${ }^{3}$ Leticia \\ Marissolde Souza Francisco,' Samantha \\ Lorena Paganelli ${ }^{4}$ \\ 'Department of Neurosurgery, Hospital Celso Pierro, Brazil \\ ${ }^{2}$ Department of Neurosurgery, Hospital Santa Paula, Brazil \\ ${ }^{3}$ Department of Neurosurgery, Hospital AC Camargo Cancer \\ Center, Brazil \\ ${ }^{4}$ Department of Neurosurgery, Hospital Ramos Mejía, Buenos \\ Aires University, Argentina
}

Correspondence: Maick Willen Fernandes Neves, Medical Resident, Department of Neurosurgery, Hospital Celso Pierro, PUC Campinas, Campinas, Avenidalbijaú 368, Moema, São Paulo, SP, Brazil, CEP 04524-02,; Email maickfernandes@gmail.com

Received: November 17, 2017 | Published: December 29, 2017

\section{Introduction}

Cavernoma is the most common vascular malformation of the brain with an incidence of $0.4-0.5 \%$, prevalence of 0.6 per 100,000 inhabitants, predominance in males between 20-40 years old, and predominance of $25 \%$ in children. ${ }^{1-4}$ Brainstem cavernomas are rare $(18 \%)$ and present a bleeding rate higher than supratentorial cavernomas; they are more common in the pons $(61 \%)$, with an estimated bleeding rate of $2-6.6 \%$ per year. ${ }^{1,5-8}$ In the pediatric population, the lesion is found in the pons (rate of $73 \%$ ), and it presents a $12.3 \%$ rate of bleeding per year and a $32.5 \%$ rate of rebleeding per year. ${ }^{9}$

There is a genetic inheritance relationship, autosomal dominant, associated to the CCM1 gene (cerebral cavernous malformation 1), CCM2, and CCM3. ${ }^{2}$ CCM1 is located on chromosome 7 at band 7q11.2-q21, CCM2 is located at band 7p15-p13, CCM3 is located on chromosome 3 at band $3 \mathrm{q} ; 40 \%$ are located in mutation 1 and $20 \%$ in mutation $2 .{ }^{4}$ When it is related to family inheritance, there is a higher chance of multiple cavernomas and a higher rate of hemorrhage. ${ }^{2}$

\section{Materials and methods}

Articles were searched on PUBMED and they were based on the treatment of ventral pontine cavernomas and anterolateral pontine cavernomas; these articles were critically analyzed and tables were constructed for data analysis.

\section{Results and discussion}

The diagnosis is performed by magnetic resonance imaging (MRI) and clinical presentation; the most common symptoms are hemorrhage, seizure, gaze palsy, diplopia, obstructive sleep apnea, vertical and torsional eye movements, gait disturbance, headache, and focal deficit. Cavernomas can also be diagnosed unexpectedly. ${ }^{1,4,10-13}$ The risk of bleeding ranges from $5 \%$ to $6.6 \%$ per year and the risk of rebleeding ranges from $26 \%$ to $30 \% .^{1,8}$ Therefore, the treatment should always be performed in adults. In the pediatric population, the indication includes multiple hemorrhages, lesions equal or bigger than $2 \mathrm{~cm}$, severe or progressive deficits, exophytic lesions, and mass effect on the brainstem. ${ }^{9}$

The treatment of choice is surgery, 4-6 weeks after bleeding, although the time is still controversial because the approach is easier in the period that the hematoma is not yet organized; in this case, the goal is the complete removal, preventing recurrence of bleeding and functional worsening. ${ }^{1,14,15}$ However, before indicating the surgical procedure, the main differential diagnosis (pontine glioma and multiple sclerosis) must be excluded. ${ }^{16}$

Brainstem cavernomas located on the pons are classified in dorsal, lateral, and ventrolateral. ${ }^{17}$ Accesses to approach the anterior region of the pons are dangerous due to the risk of corticospinal tract lesions and worsening of postoperative deficits. Anterolateral accesses have been used for ventromedial lesions due to the corticospinal tract in the ventromedial region of the pons. ${ }^{18}$ Peng Hu et al. ${ }^{17}$ observed that the retrosigmoid approach was mostly chosen in 83 patients with cavernomas in the ventrolateral region of the pons (Table 1).

Gross et al. ${ }^{19,20}$ performed a meta-analysis with 1390 patients and obtained a total resection rate of $91 \%$ and a mortality rate of $1.5 \%$. Another meta-analysis performed by the same authors with 683 patients showed a worsening of neurological deficits in $14 \%$ of the patients and a mortality rate of $1.9 \%$. In the first analysis, the following approaches were observed for cavernomas of the anterior part of the brainstem: retrosigmoid, anterior transpetrosal (Kawase), and presigmoid/retrolabyrinthine. 
Table I Surgical approaches in the ventrolateral region of the pons

\begin{tabular}{lc} 
Retrosigmoid approach & $49,4 \%$ \\
$\begin{array}{l}\text { Presigmoid approach } \\
\begin{array}{l}\text { Subtemporal approach or sub temporal combined with } \\
\text { suboccipital approach }\end{array}\end{array}$ & $13,3 \%$ \\
Transpetrosal approach & $9,3 \%$ \\
\hline
\end{tabular}

The size of the cavernoma or hematoma is not associated with surgical success and the hematoma facilitates dissection; however, when bleeding occurs again, the dissection is difficult due to the formation of a fibrous capsule. ${ }^{21}$ The entry region in the anterolateral part of the pons is in the safe zone, $1 \mathrm{~cm}$ lateral to the ventromedial region towards the root of the $\mathrm{V}$ nerve, approximately $1 \mathrm{~cm}$ in size; this approach must be used to minimize deficits. ${ }^{17}$

The classic retrosigmoid approach (Figure 1) presents the ventral part of the pons as a limitation; the extension of this approach is an alternative, with removal of a part of the mastoid bone and the temporal bone and a $50 \%$ increase of the angle of vision, which allows the ventral approach with lower cerebellar traction. ${ }^{22}$ Hauck EF et al. ${ }^{23}$ described 9 cases using pre sigmoid approach (Figure 2) with access to the lateral part of the pons, between the facial and trigeminal nerves, perpendicularly towards the brainstem.
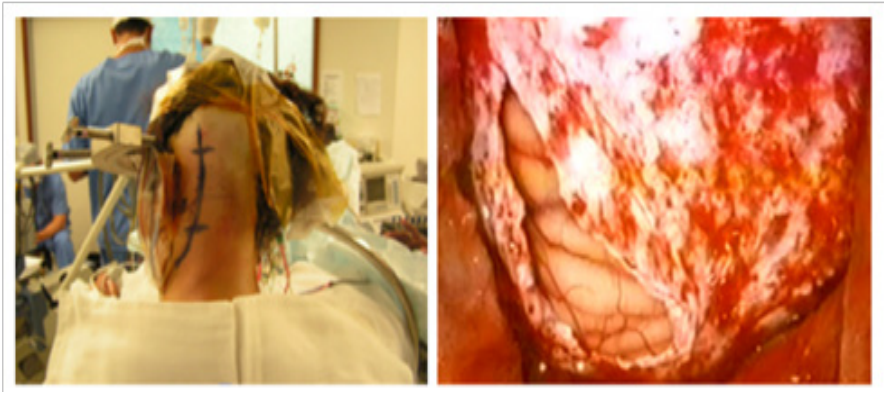

Figure I A: Skin markin the retrosigmoid approach in a semi-seated position. B: Dural opening adjacent to the left sigmoid sinus.
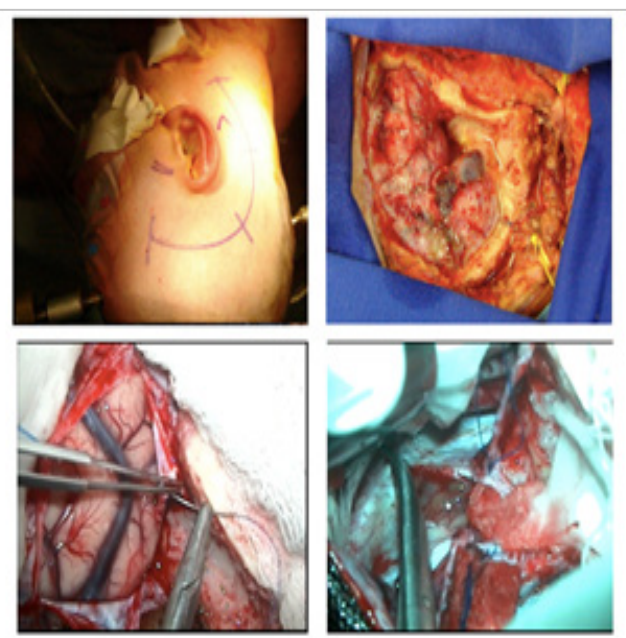

Figure 2 A: Skin mark for the cut in the right presigmoid.

B: Craniotomy with exposure of the middle cranial fossa and duramater view.

C: Middle cranial fossa opening.

D: Cerebellar tentorium opening.
Sub temporal transtentorial approach is used for cavernomas located at the top of the pons; the access is performed through the middle cranial fossa with temporal lobe retraction, cut of the cerebellar tentorium, but only after the identification of the IV nerve. ${ }^{15}$

Anterior transpetrosal approach (Kawase approach) is indicated for lesions located in the inferior part of the pons with access through the middle fossa, extensive dissection, drilling of the petrous apex, and opening of the tentorium, visualizing the superior petrosal sinus. ${ }^{5,15}$ Peng Hu et al. ${ }^{17}$ used this approach in $9.6 \%$ of the cases and Alba et al used this approach in $5 \%$ of the cases.

Far lateral approach (Figure 3) is indicated for lesions located in the lower clivus in the anterior part of the pons; as an advantage, it presents a smaller retraction of the cerebellum and brainstem. However, this approach requires a long surgery and can cause craniocervical instability and vertebral artery lesion. ${ }^{8}$ Trans oral transclival approach (Figure 4) is an alternative for these lesions located in the lower part of the pons. ${ }^{15}$

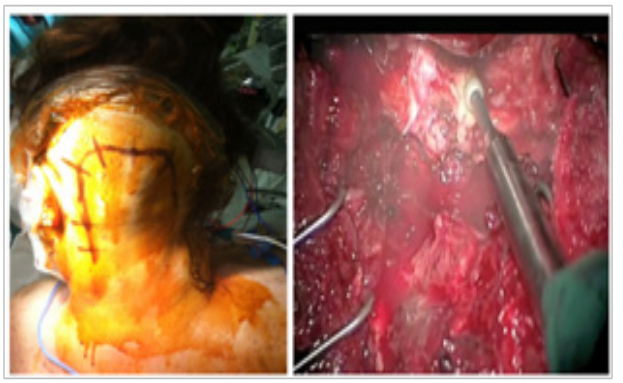

Figure 3 A: Skin mark in the far lateral approach.

B: Dissection with drilling of the left occipital condyle.

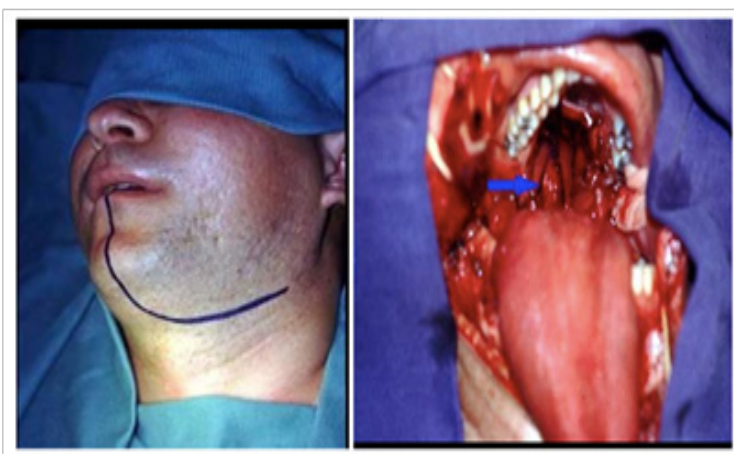

Figure $4 \mathrm{~A}$ : Skin mark in the transoral transclival approach. $\mathrm{B}$ : Opening of the anterior part of the clivus.

Endonasal transclival approach is indicated for cavernomas in the ventromedial region of the pons because it presents a direct access and manipulates less the cerebral tissue, which reduces postoperative morbidity and hospitalization time (Figure 5). The complication of this approach is the risk of cerebrospinal fluid leak, even though it can be minimized with lumbar drainage and small bone defects. ${ }^{1,3}$ The endoscopy requires a great surgical ability and adequate tools; the surgeon must be trained and the equipment must be available. Kassan et al. ${ }^{24}$ classified the complexity of endoscopic lesions from I to V; anterior pontine cavernomas have a classification $\mathrm{V}$.

Postoperative rebleeding is associated with residual cavernoma; however, the presence of asymptomatic residual lesion does not justify a new surgical procedure. ${ }^{9,18}$

Radiosurgery is not the first-choice treatment because of a $14 \%$ to 
$40 \%$ risk of bleeding during the latency period of the treatment and its complications are directly related to the dose of radiation used. ${ }^{15}$ It is an alternative for lesions that are considered unresectable and observation must be chosen. ${ }^{2}$

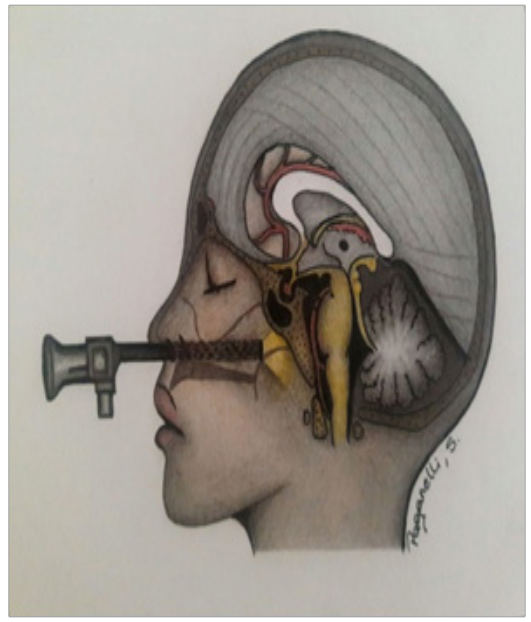

Figure 5 Endoscopic approach to the clivus.

Neuroendoscopy, neurophysiological monitoring, tractography, intraoperative ultrasound, and neuronavegation are extremely useful nowadays. The diffusion tensor imaging (DTI) tractography demonstrated the displacement of the corticospinal tract and can facilitate the surgical procedure. ${ }^{25}$ Neurophysiological monitoring during the procedure of dissection and excision of the lesion is extremely useful for the monitoring of corticospinal tract lesions.

Table 2 Cavernomas approaches.

\begin{tabular}{ll}
\hline Upper pons & Lower pons \\
\hline $\begin{array}{l}\text { Endoscopic approach } \\
\text { Subtemporal transtentorial } \\
\text { approach }\end{array}$ & Endoscopic approach \\
$\begin{array}{l}\text { Presigmoid approach } \\
\text { Retrosigmoid approach }\end{array}$ & TransoralTransclival approach \\
\hline
\end{tabular}

\section{Conclusion}

Anterior pontine cavernomas have a high risk of bleeding and an extremely high risk of rebleeding; therefore, they must be treated as soon as they are diagnosed due to the high risk of morbidity and mortality. The treatment is through surgery and the approach must be chosen depending on the topography in the upper and lower part of the pons and the ability of the neurosurgeon with the endoscope. Total resection and the cure of the lesion must always be aimed.

\section{Financial support and sponsorship}

Nil.

\section{Acknowledgements}

None.

\section{Conflicts of interest}

The author declares no conflicts of interest.

\section{References}

1. Banczerowski P, Czigléczki G, Gàdor I. Long-term outcome of endonasal transsphenoidal approach for the treatment of pontine cavernous malformation: case report with 11 years of follow-up. J Neurol Surg A Cent Eur Neurosurg. 2016;77(3):269-273.

2. Bradac O, Majovsky M, de Lacy P, et al. Surgery of brainstem cavernous malformations. Acta Neurochir. 2013;155(11):2079-2083.

3. Linsler S, Oertel J. Endoscopic endonasal transclival resection of a brainstem cavernoma: A detailed account of our technique and comparison with the literature. World Neurosurg. 2015;84(6):2064-2071.

4. Menon A, Kanchan T, Lobo FD, et al. Pontine cavernous haemangioma - An incidental autopsy finding. J Forensic Leg Med. 2009;16(7):417419

5. Abla AA, Benet A, Lawton MT. The far lateral transpontomedullary sulcus approach to pontine cavernous malformations: Technical report and surgical results. Neurosurgery. 2014;10(Suppl 3):472-480.

6. Cohen Gadol AA. Large pontine cavernous malformations: resection via the telovelar approach and mapping of the fourth ventricular floor: 3-dimensional operative video. Neurosurgery. 2014;10(Suppl 4):655.

7. Dallan I, Battaglia P, de Notaris M, et al. Endoscopic endonasal transclival approach to a pontine cavernous malformations: case report. Int $J$ Pediatr Otorhinolaryngol. 2015;79(9):1584-1588.

8. Garber ST, Couldwell WT. Resection of an inferior pontine cavernous malformation using a far-lateral transcondylar approach. Acta Neurochir. 2011;153(12):2461-2464.

9. Li D, Hao SY, Tang J, et al. Surgical management of pediatric brainstem cavernous malformations. J Neurosurg Pediatr. 2014;13(5):484-502.

10. Kagitani Shimono K, Kato Nishimura K, Okinaga T, et al. Long-term observation of absence of REM sleep caused by pontine cavernous hemangioma. Sleep Med. 2011;12(10):1045-1046.

11. Kashimura $\mathrm{H}$, Inoue $\mathrm{T}$, Ogasawara $\mathrm{K}$, et al. Pontine cavernous angioma resected using the sub temporal anterior approach determined using three-dimensional anisotropy contrast imaging: technical case report. Neurosurgery. 2006;58(1suppl):ONS-E175.

12. Yamamoto R, Nishiyama T, Kurokawa T, et al. A case of cavernous angioma in the lower pons, showing subacute onset of unilateral cranial nerve palsy and segmental sensory disturbance. Rinsho Shinkeigaku. 2009;49(1):32-36

13. Washio N, Suzuki Y, Yamaki T, et al. Vertical-torsional oscillations and dissociated bilateral horizontal gaze palsy in a patient with a pontine cavernounsangioma. J Neurol Neurosurg Psychiatry. 2005;76(2):283-285.

14. Fahlbush R, Strauss C, Huk W, et al. Surgical removal of pontomesencephalic cavernous hemangioma. Neurosurgery. 1990;26(3):456-457.

15. François $\mathrm{P}$, Ben Ismail $\mathrm{M}$, Hamel $\mathrm{O}$, et al. Anterior transpetrosal and subtemporaltranstentorial approach for pontine cavernomas. Acta Neurochir (Wien). 2010;152(8):1321-1329.

16. Ming X, Gonzales C, Burrowes D, et al. Cavernous angioma of the brain stem simulating diffuse pontine glioma. J Child Neurol. 2001;16(8):614 615

17. Hu P, Liang J, Bao Y, et al. The pterional transsylviantranstentorial approach to ventrolateral pontine cavernomas: indications and techniques. World Neurosurgery. 2014;82(6):1276-1282.

18. Sanborn MR, Kramarz MJ, Storm PB, et al. Endoscopic, endonasal, transclival resection of a pontine cavernoma: Case report. Neurosurgery. 2012;71(1Suppl Operative):198-203. 
19. Gross BA, Bater HH, Award IA, et al. Brainstem cavernous malformations. Neurosurgery. 2009;64(5):E805-818.

20. Gross BA, Bater HH, Awad IA, et al. Brainstem cavernous malformations: 1390 surgical cases from the literature. World Neurosurg. 2013;80(1-2):89-93.

21. Wang CC, Liu A, Zhang JT, et al. Surgical management of brain-stem cavernous malformations: report of 137 cases. Sure Neurol. 2003;59(6):444-454.

22. Ceylan D, Tatarli N, Seker A, et al. Surgical exposure gained in an extended retrosigmoid approach to the cerebellopontine angle compared to the traditional retrosigmoid approach. Turk Neurosurg. 2015;25(5):728736.
23. Hauck EF, Barnett SL, Write JA, et al. The presigmoid approach to anterolateral pontine cavernomas. Clinical article. J Neurosurg. 2010;13(4):701-708.

24. Kassan AB, Thomas A, Carrau RL, et al. Endoscopic reconstruction of the cranial base using pedicled nasoseptal flap. Neurosurgery. 2008;63(1Suppl 1):ONS44-52.

25. Chu ER, Chen CS, Patel S, et al. Displaced corticospinal fibre tracts by a pontine cavernous. Intern Med J. 2009;39(12):849. 